Cochrane Database of Systematic Reviews

\title{
Interventions using social networking sites to promote contraception in women of reproductive age (Review)
}

Jawad A, Jawad I, Alwan NA

Jawad A, Jawad I, Alwan NA.

Interventions using social networking sites to promote contraception in women of reproductive age.

Cochrane Database of Systematic Reviews 2019, Issue 3. Art. No.: CD012521.

DOI: 10.1002/14651858.CD012521.pub2.

www.cochranelibrary.com 
TABLE OF CONTENTS

HEADER 1

ABSTRACT

PLAIN LANGUAGE SUMMARY

BACKGROUND

OBJECTIVES

METHODS

Figure 1.

RESULTS

Figure 2.

Figure 3.

DISCUSSION

AUTHORS' CONCLUSIONS

ACKNOWLEDGEMENTS

REFERENCES

CHARACTERISTICS OF STUDIES

APPENDICES

CONTRIBUTIONS OF AUTHORS

DECLARATIONS OF INTEREST

SOURCES OF SUPPORT

DIFFERENCES BETWEEN PROTOCOL AND REVIEW

INDEX TERMS 
[Intervention Review]

\section{Interventions using social networking sites to promote contraception in women of reproductive age}

Aalaa Jawad 1 , Issrah Jawad², Nisreen A Alwan³,4

1Public Health Training Programme, Health Education England, London, UK. 2Department of Obstetrics and Gynaecology, Queen Charlotte's Hospital, London, UK. ${ }^{3}$ School of Primary Care and Population Sciences, Faculty of Medicine, University of Southampton, Southampton, UK. ${ }^{4}$ NIHR Southampton Biomedical Research Centre, University of Southampton and University Hospital Southampton NHS Foundation Trust, Southampton, UK

Contact address: Aalaa Jawad, Public Health Training Programme, Health Education England, Stewart House, 32 Russell Square, London, WC1B 5DN, London, UK. aalaa.jawad@gmail.com.

Editorial group: Cochrane Fertility Regulation Group.

Publication status and date: New, published in Issue 3, 2019.

Citation: Jawad A, Jawad I, Alwan NA. Interventions using social networking sites to promote contraception in women of reproductive age. Cochrane Database of Systematic Reviews 2019, Issue 3. Art. No.: CD012521. DOI: 10.1002/14651858.CD012521.pub2.

Copyright ( 2019 The Cochrane Collaboration. Published by John Wiley \& Sons, Ltd.

\section{A B S T R A C T}

\section{Background}

Social networking sites (SNSs) have great potential as a platform for public health interventions to address the unmet need for contraception.

\section{Objectives}

To evaluate the effectiveness of interventions using SNSs to promote the uptake of and adherence to contraception in reproductive-age women.

\section{Search methods}

We searched CENTRAL, MEDLINE, Embase, and six other databases on January 2018. We also searched Google Scholar, key conference proceedings, checked the reference lists of included studies, and contacted study authors to identify additional studies.

\section{Selection criteria}

We considered randomised controlled trials (RCTs) and non-randomised interventional studies (NRS) in women of reproductive age. SNSs requiring a social profile within a bounded or restricted-access system of shared connections were included. We also included trials that utilised SNSs only or as an adjunct to an intervention. Studies had to have a follow-up outcome assessment of at least three months.

\section{Data collection and analysis}

Two authors independently screened titles, abstracts and full-text studies, and extracted data from included studies. A third author was assigned to arbitrate areas of disagreement. Authors assessed risk of bias according to the Cochrane Handbook for Systematic Reviews of Interventions. We were unable to conduct a meta-analysis due to the heterogeneity of the study designs and outcome measures.

\section{Main results}

Of the 461 unique records found, only two studies met our inclusion criteria. Both studies were conducted in the USA and were at high risk of bias. One RCT included 2284 women exposed to a web-based SNS or nothing. The groups were no different post intervention in their self-reported consistency of contraceptive use or knowledge of the relative effectiveness of different methods. There was a small but significant increase in the use of more effective methods (long-acting reversible methods) at 12 months' follow-up. 
The second study, a cluster RCT with 1578 women, used a closed Facebook page showing sexual health content compared to a modified Facebook news page that avoided sexual health content. They found no differences in the use of condoms at last act of sexual intercourse at six months or the intention to use condoms between the intervention and control groups.

\section{Authors' conclusions}

Despite the prevalence of SNSs, we found little scientific evidence to support the use of SNSs to improve contraceptive use or adherence among women.

\section{PLAIN LANGUAGE SUMMARY}

\section{Interventions delivered by social networking sites to support women's use of contraception}

\section{Background}

Unplanned pregnancies have a big impact on the health and well-being of women, their families, and their communities. Social networking sites (SNSs) such as Facebook and Instagram are popular globally, but their potential in helping to improve contraceptive use has not been fully explored.

\section{Objectives}

To evaluate the effectiveness of using SNSs to promote the uptake of and adherence to contraception in reproductive-age women.

\section{Search methods}

We ran an electronic search in January 2018 on several online databases and key conferences to identify relevant studies that used SNSs to improve contraceptive use in reproductive-age women.

\section{Selection criteria}

To be included, studies must have used an SNS (either alone or with another method), and have followed the women involved for at least three months after the intervention.

\section{Data collection and analysis}

Two authors independently screened titles, abstracts and full-text studies, and extracted data from included studies. A third author was assigned to resolve areas of disagreement.

\section{Main results}

We reviewed 461 titles, abstracts and full-text articles and found only two studies that met the inclusion criteria. Both studies were conducted in the USA and had a high risk of bias. The first study divided women into two groups; one group received access to a website containing highly accurate medical information about contraception for the public called Bedsider.org, while the other group was exposed to nothing. The study found no differences between the groups in how consistently women used a contraceptive method, or their knowledge of how well each method prevented pregnancy. However, this study did find that more women in the group exposed to Bedsider.org used a highly effective contraceptive method one year later.

The second study used a closed Facebook page exposing women to either sexual health content or news articles that avoided sexual health information in order to determine the impact on condom use. The study found no difference between groups in how consistently condoms were used six months postintervention or their intention to use condoms in the future.

\section{Authors' conclusions}

We found little scientific evidence available to support whether SNSs improve contraceptive use or continuation among women. 


\section{B A C K G R O U N D}

\section{Description of the condition}

Contraception is a key public health intervention to prevent unintended pregnancy. Unintended pregnancy is common globally, and has negative health consequences for both women and children (Cleland 2012). Consistent and correct contraceptive use can play a key role in reducing the rates of maternal mortality and unsafe abortion, as well as improve perinatal outcomes and child survival (Cleland 2012). Unplanned pregnancy is associated with worse maternal health outcomes, including obstetric complications, postnatal depression (Wellings 2007), and poor birth outcomes including premature birth and low birth weight (Kuroki 2008). It can increase the risk of adverse family socioeconomic outcomes and family dysfunction (Boden 2015), and risk factors include young maternal age, unmarried status and low educational attainment (Kuroki 2008). Of particular note, teenage pregnancies are complicated by increased levels of morbidity and mortality, higher rates of abortion and can "set the pattern for the rest of an individual's life" (WHO 2004).

Globally rates of contraception usage vary. In 2015, the United Nations (UN) reported that a mean of $64 \%$ of married or in-union women of reproductive age use some form of contraception. The rates of contraception use were highest (75\%) in North America and lowest (33\%) in Africa (UN 2015). The UN identified that around one in 10 married or in-union women worldwide were estimated to have an unmet need for family planning (UN 2015). This unmet need was particularly apparent among adolescents where contraception use and adherence in this age group was varied (UN 2015). One study using nationally representative data from the USA found that younger teenage girls (who started having sex at age 14 years or younger) were less likely to have used a method at first sex and take longer to begin using contraception (Finer 2013). Resolving this unmet need for contraception is a vital global public health goal (Alkema 2013; Gold 2011).

\section{Description of the intervention}

With the rapid expansion of social networking sites (SNSs), SNSs are now considered a component of daily life (Gold 2012; Xu 2012). Boyd 2007 defined SNSs as "web-based services that allow individuals to (1) construct a public or semi-public profile within a bounded system, (2) articulate a list of other users with whom they share a connection, and (3) view and traverse their list of connections and those made by others within the system."

SNSs range greatly in their focuses from social utility, such as Facebook; microblogging, such as Twitter; to business, such as LinkedIn. Facebook is considered the most popular (Gold 2012), and is the third most popular webpage worldwide with Twitter, LinkedIn and Instagram also in the top 25 (Alexa 2016). The definition of social media is broad and can include a diverse set of platforms; for this review, we focused on SNSs that are unique in that they require the creation of a social profile within a bounded system that allows users to share connections (Boyd 2007).

Reports from the USA show that $69 \%$ of internet users use at least one social media site. The heaviest users were 18- to 29-year olds with $88 \%$ using at least one social media site (Pew Research Center 2018). Similarly, in the UK, $81 \%$ of the general public report using social media daily, with $44 \%$ of 16 - to 24 -year olds visiting sites more than 10 times a day (Ofcom 2015). Women use social media more often and more extensively than their male counterparts, with data from the UK reporting $78 \%$ of women more likely to have a social media profile or account compared to $73 \%$ of men (Ofcom 2017). Similar reports from the USA estimate the $73 \%$ of women use at least one social media site compared to $65 \%$ of men in 2018 (Pew Research Center 2018). Globally, SNS usage continues to grow with worldwide internet users spending 106 minutes daily (Statista 2015). Their use as a health intervention has become increasingly championed in research (Gold 2011; Gold 2012), and the popularity, widespread accessibility and ease of use makes them a key vehicle for health interventions.

SNS interventions are run in various ways, with many studies using them as an add-on to standard treatment. While their use is highly advocated by some (Gold 2012; Korda 2013), others argue that social media is insufficient as a stand-alone intervention for health promotion and poses a risk of providing misleading or inaccurate information (Balatsoukas 2015). One RCT of 143 women in the USA used a Facebook account as an adjunct to inoffice counselling and found improved participant contraceptive knowledge and increased preference for long-acting reversible contraceptives (Kofinas 2014). A second RCT of 190 users of the Myspace SNS aimed to reduce the display of risky sexual behaviour by sending a single physician email to targeted users considered 'at risk.' They reported an increase in protective changes made on individual profiles in the intervention group compared to the control group who received no contact (Moreno 2009).

\section{How the intervention might work}

SNS-based interventions can be broadly categorised as follows.

- Interventions that create an account that participants chose to interact with. This can be an account created with the aim of health promotion. Generally, this is expected to be an open account that users choose to follow or receive ongoing posts or discussions.

- Interventions that create an account and directly contact participants through private messages or 'emails.' In this approach, the intervention would actively recruit participants and use private messaging or in-app email to directly target users of the SNSs.

- Interventions that create character accounts that participants can chose to follow or interact with. These interventions will pose as an active account that generates a following, or interacts with users in live-time to deliver the intervention.

- Interventions that do not use an intervention account to deliver health promotion. By discussing or sharing information in groups or networks the intervention may be carried out without any direct user contact and rely on peer-effect instead.

SNS-based interventions may work in isolation to educate or counsel participants or in adjunct to other interventions. They should aim to initiate or improve uptake of contraception methods and improve adherence, or both uptake and adherence.

In understanding how the intervention might work, motivational theory is commonly used to describe the use of social media. This theory identifies with intrinsic motivation characterised by the "hedonic" enjoyment of using it, in addition to the extrinsic motivations of utilitarian gratification and perceived usefulness (Xu 2012). The extrinsic motivations were expanded on to explain 
that the network externality came from the number of members, number of peers and perceived similarity, which all interplay in the continued use of social media (Lin 2011). Thus the use of SNS is a complex interplay of network externalities, usefulness and enjoyment (Lin 2011).

\section{Why it is important to do this review}

Reducing unmet need for contraception, and thus unintended pregnancy, is a public health priority. Unintended pregnancy is associated with significant health and socioeconomic implications for women and their children (Cleland 2014; UN 2015; WHO 2004). The value of SNSs as a health intervention has been recognised (Gold 2012; Guse 2012). One comprehensive metaanalysis that explored the effect of SNS health interventions on non-communicable diseases found a positive effect on healthrelated behaviour outcomes (Laranjo 2015).

We found no previous review exploring the impact of SNS interventions on the uptake of, adherence to, or both uptake and adherence to contraception specifically. By narrowing the scope and focusing solely on SNSs, as opposed to the umbrella term of social media which encompasses a variety of platforms, we can assess the impact of SNS interventions on the use and adherence of contraception, and identify the need for further research.

\section{O B JECTIVES}

To evaluate the effectiveness of interventions using SNSs to promote the uptake of and adherence to contraception in reproductive-age women.

\section{METHODS}

\section{Criteria for considering studies for this review}

\section{Types of studies}

We considered interventional studies including randomised controlled trials (RCTs) and non-randomised interventional studies (NRS) to include non-RCTs. We expected limited evidence from RCTs that utilised an SNS as an intervention. Thus, we included NRS to examine the evidence base broadly.

\section{Types of participants}

Women of reproductive age who may have initiated contraceptive use, switched to a different method or continued to use the same method. Reproductive age was defined as between 15 and 49 years of age as per the World Health Organization (WHO) definition (WHO 2006). In studies that included both sexes, we requested results pertaining to women from the authors. Postpartum or postabortal women were also included.

\section{Types of interventions}

We included studies where the intervention was delivered either solely via a named SNS, or in conjunction with another method. We included interventions if the purpose was to improve uptake and adherence, or both uptake and adherence to contraception compared to standard delivery of care or another intervention.

The included interventions fulfilled one of the following aims:

- improved uptake of contraception;

- promoted use of a specific contraceptive method;
- promoted uptake of more effective contraceptive methods;

- improved adherence to contraception; and

- both improved uptake and adherence to contraception.

Interventions were included if they targeted current and potential contraception users. The authors definition of more effective contraceptive methods was accepted, although this was likely to include long-acting reversible contraceptive methods. The interventions had to be delivered through named SNSs where the participant had a personal account that allowed them to access the intervention. Although not an exclusion criteria, SNSs were expected to allow participants to interact with each other. We excluded any intervention delivered by an application or website where a personal account was not required, where the intervention could only be utilised when downloaded, or if participants could not interact with the intervention directly. We included SNSs available in a downloadable form only if they also had an openaccess website.

\section{Types of outcome measures}

\section{Primary outcomes}

- Contraception use (for at least three months postintervention), which included:

* initiation of a new method;

* increased uptake of more effective methods;

* improved adherence to a method; and

* both increased uptake and improved adherence.

Contraception use was be assessed in various ways, and we accepted the method used by the trial investigator.

The time frame for assessment was three months or more for the initiation of a new method and improved adherence of an existing method as defined by the study.

\section{Secondary outcomes}

- Change in attitude or knowledge about contraception.

- Attitudes towards the use of SNSs as an intervention.

\section{Search methods for identification of studies}

\section{Electronic searches}

We conducted a systematic search for eligible studies in the following databases without language or publication status restrictions. Searches started from 1997, when the first SNS (according to the definition we outlined earlier) was created (Boyd 2007). The search strategies for the complete list of search terms are in Appendix 1.

We searched the following databases:

- the Cochrane Central Register of Controlled Trials (CENTRAL; 2018, Issue 1) in the Cochrane Library (searched 15 January 2018);

- MEDLINE Ovid (1997 to 15 January 2018);

- Embase Ovid (1997 to 15 January 2018);

- CINAHL EBSCO (Cululative Index to Nursing and Allied Health Literature; 1997 to 15 January 2018);

- Web of Science (1997 to 15 January 2018);

- ACM Digital Library (1997 to 15 January 2018); and 
- DBPL computer science bibliography (dblp.uni-trier.de/search; searched 15 January 2018).

We searched the following trial registries:

- ClinicalTrials.gov (clinicaltrials.gov; searched 15 January 2018); and

- WHO International Clinical Trials Registry Platform (apps.who.int/trialsearch/; searched 15 January 2018).

\section{Searching other resources}

We contacted authors of included studies to request additional information about the study or, where appropriate, to identify any additional trials. We searched references of included studies, reviewed abstracts of key sexual and reproductive health conferences, and searched Google Scholar for grey literature.

\section{Data collection and analysis}

\section{Selection of studies}

We assessed all titles and abstracts identified during the literature search for inclusion. We exported the search results into a bibliographic citation management software programme and removed duplicates using Endnote X6 (Endnote X6). Two authors independently screened the titles and abstracts of the retrieved records; citations selected by either author were included for full-text screening. We retrieved full texts of articles for further assessment according to the following criteria:

- included women of reproductive age and users, or potential users, of contraception;

- had an intervention delivered by a SNS as a stand-alone intervention or as an adjunct with another method; and

- compared the intervention to routine standard of care or another intervention.

If there was any doubt regarding the criteria from the information in the title and abstract, we retrieved the full-text article for clarification. Two authors assessed the full-text articles of potential eligible studies independently and in duplicate. We resolved discrepancies by discussion or by consultation with a third author. We listed studies excluded after full-text assessment in the Characteristics of excluded studies table with their reasons for exclusion. We constructed a PRISMA diagram to illustrate the study selection process (Figure 1).

Figure 1. Study flow diagram. SNS: social networking site.

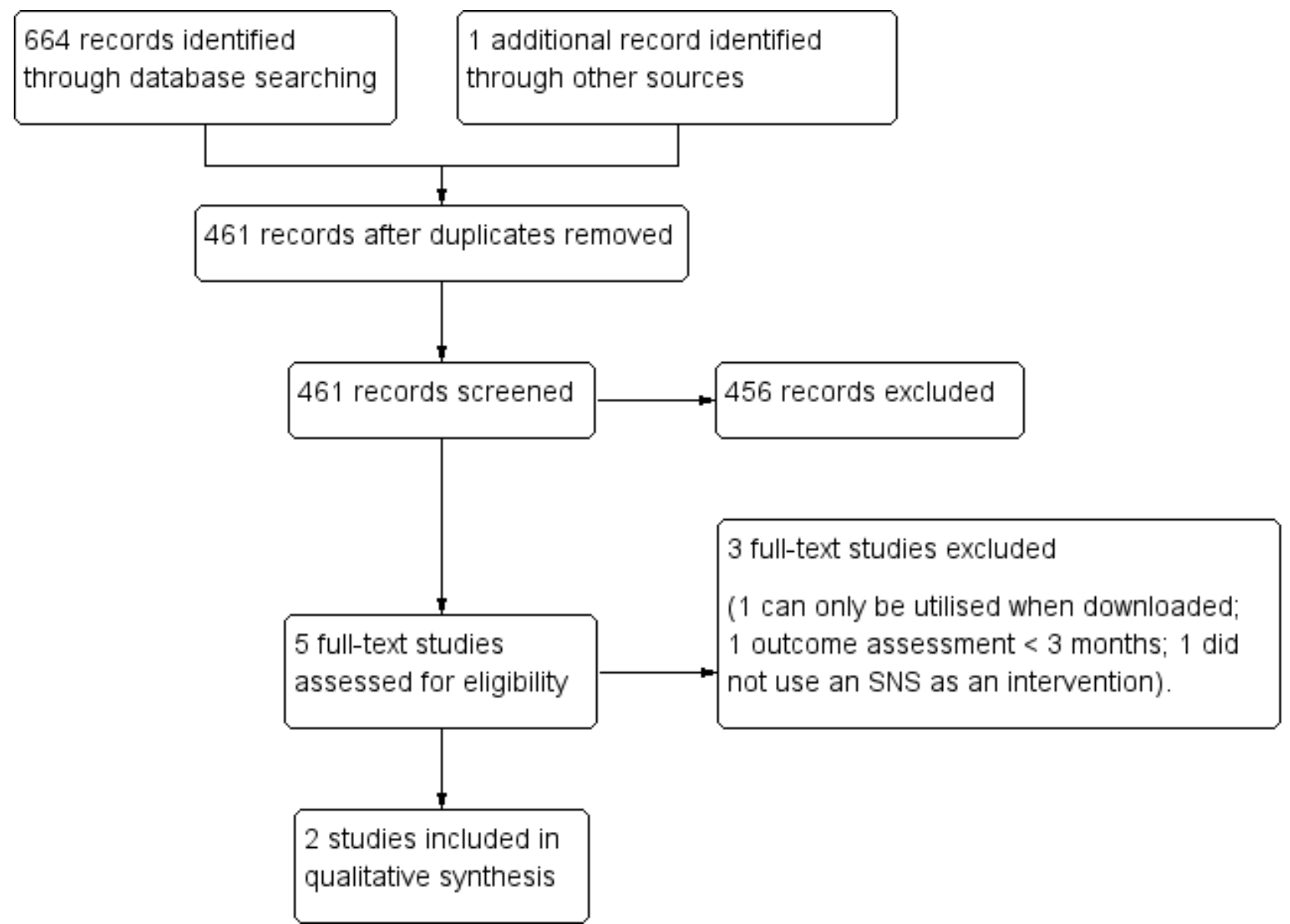




\section{Data extraction and management}

Two authors independently extracted data from each of the included trials. We focused on the primary and secondary outcomes for this review and we resolved any discrepancies through discussion with a third author. Due to the limited number of studies identified, and differences in how and when outcomes were measured, combining studies in a 'Summary of findings' table using GRADEpro GDT 2014 was not feasible.

\section{Assessment of risk of bias in included studies}

We assessed the risk of bias in each included study in accordance with the Cochrane Handbook for Systematic Reviews of Interventions (Higgins 2011). For RCTs, we examined sequence generation, allocation concealment, blinding, incomplete outcome data, selective outcome reporting, and other potential biases. For NRS, we planned to use the GRADE 'Risk of bias' framework (Guyatt 2011), which reported on the eligibility criteria, measurement of exposure, measurement of outcome, confounding, and attrition rates.

Two authors independently assessed the risk of bias of each included study. We resolved any disagreement through discussion with a third author. We were unable to conduct further data analysis on the studies given the heterogeneity in outcome measures collected and reported, and the unclear risk of bias.

\section{Measures of treatment effect}

For dichotomous outcomes, we planned to determine the odds ratios and 95\% confidence intervals (Cls) and for continuous variables, to calculate the mean difference with $95 \% \mathrm{Cls}$. However we were unable to obtain adequate data from included studies to determine these effect measures.

\section{Unit of analysis issues}

The unit of analysis was the individual women. In clusterrandomised studies, we assessed whether the study authors had appropriately adjusted and accounted for clustering within their analysis.

\section{Dealing with missing data}

Due to the varied nature of possible interventions we did not expect all included studies to have addressed all the outcomes that we examined. In cases of missing data, we contacted the primary study investigators to request additional information to address this. We received a reply from one study where we were provided with the effect sizes of requested outcomes to reflect females only (outcomes were calculated as Cohen's d) (Bull 2012), and received no communication from the second study (Antonishak 2015). We assumed the data were missing at random and discussed this in the Discussion section of the review.

\section{Assessment of heterogeneity}

We were unable to conduct a meta-analysis as the included studies were of variable designs. We visually examined heterogeneity by comparing study designs, target populations, and primary outcome measures across included studies.

\section{Assessment of reporting biases}

We minimised reporting bias by using a comprehensive search strategy. If an included study insufficiently reported an outcome measure, we contacted the study authors to obtain additional information. We were unable to perform a funnel plot to identify reporting biases as there was an insufficient number of studies.

\section{Data synthesis}

Given the high heterogeneity in the studies, we were unable to conduct a meta-analysis. We assessed the risk of bias based on the Cochrane Handbook for Systematic Reviews of Interventions (Higgins 2011). There were no included NRS where we planned to use the GRADE approach to assess the quality of the evidence (Guyatt 2011). We assessed the methods used by authors to account for clustering where appropriate.

\section{Subgroup analysis and investigation of heterogeneity}

We were unable to conduct subgroup analyses based on study type (randomised or non-randomised) due to the small number of included studies. Heterogeneity was examined visually as described above.

\section{Sensitivity analysis}

We were unable to undertake any sensitivity analysis due to the small number of studies.

\section{RES U L T S}

\section{Description of studies}

\section{Results of the search}

We conducted searches in April 2017 and updated them in January 2018. Our search identified 665 records, with 461 records remaining after removal of duplicates. Our screening of titles and abstracts excluded 456 records, leaving five records for full-text assessment for eligibility. Of the five studies, two were eligible and are reported in the Characteristics of included studies table. We reported the three excluded studies in the Characteristics of excluded studies table, which includes the reasons for exclusion. The PRISMA study flowchart is presented in Figure 1.

\section{Included studies}

Two studies fulfilled our inclusion criteria, one of which used an 'online birth control support network' website called Bedsider (Antonishak 2015), and the second used Facebook (Bull 2012). Both studies were conducted in the USA.

The first study was conducted between 2012 and 2013, and was a two-arm RCT with 2284 women aged 18 to 29 years (Antonishak 2015). Participants were recruited online from a probabilitybased web panel representative of the USA. The intervention arm consisted of exposure to an online website called Bedsider.org. The intervention group was shown videos on the site and sent quarterly emails with website content, but were not directed to specific areas of the site. The control group was randomised to receive no exposure to the website and no alternative intervention or placebo.

The primary outcomes of the study were to assess whether exposure to the website improved contraceptive use (measured as self-reported use of more effective methods or more consistent use) and decreased unprotected sex. Additionally they assessed whether the intervention helped prevent unplanned pregnancy (measured as actual incidence of unplanned pregnancy and the 
incidence of pregnancy scares). Secondary outcomes included whether the intervention group would be more familiar with and knowledgeable about different methods of contraception. They reported on findings from their baseline and 12-month follow-up survey. The authors declared no funding for this study.

The second study was conducted between 2010 and 2011 and was a two-arm cluster RCT among 1578 female and male participants aged 16 to 25 years (Bull 2012). The intervention arm consisted of access to a sexual health page on Facebook. The content was based on eight broad sexual health topics, with each week devoted to a particular topic. Youth facilitators interacted with the page to post links, quizzes, games, and instigate discussion. The control group received access to a modified Facebook news page which avoided sexual health content. The clusters were groups of friends sampled through respondent-driven sampling and study authors adjusted for the effects of clustering by conducting a nested design with repeated measures techniques.

The aim of this study was to determine whether sexually transmitted prevention messages delivered via an SNS could reduce sexual risk behaviour as opposed to directly addressing contraceptive use. However, the primary outcomes were based on contraceptive use and hence were in accordance with our inclusion criteria. The primary outcomes included condom use at last sexual intercourse (measured dichotomously) and proportion of sex acts protected by condoms in the past 60 days (measured as a self-reported proportion). Secondary outcomes were a range of behavioural outcomes measured dichotomously including number of sex partners in the past two months, intention to use condoms at the next sexual encounter, and whether the most recent sex partner was considered a 'main' or primary partner, or a casual partner. Other secondary outcomes measured on a 5-point scale included substance use during their last sexual experience, peer norms for condom use, and self-efficacy for condom use. Survey data were collected at baseline, two months' follow-up, and six months' follow-up. The study was funded by the National Institute of Nursing Research.

Studies were not comparable in terms of intervention type and outcome measures. For example, one study used an open website to provide content over 12 months (Antonishak 2015), while the other used a Facebook page that delivered specific content over six months (Bull 2012). Outcome measures were measured and analysed differently, such as improved adherence being measured by proportion of sexual acts where condoms were used over the last 60 days in one study (Bull 2012), compared to the second study (Antonishak 2015), where authors predetermined a threshold of 'consistent usage' for the most popular contraceptive methods (condoms, contraceptive pill, and withdrawal) that they presented as an aggregated outcome.

\section{Excluded studies}

We excluded three studies after full-text review. The first study was a two-armed RCT conducted in Hong Kong that used a peer led Facebook group as the intervention (Sun 2017). This study was conducted in a short time frame of six weeks and participants were followed-up for less than three months. The second study was a community-based intervention study conducted in Turkey that did not use SNSs as the intervention (Hidiroglu 2016). The third study was a two-armed RCT that delivered the intervention via an app which had to be downloaded by participants (McCarthy 2017), and hence did not meet our protocol definition of SNS (Boyd 2007).

\section{Risk of bias in included studies}

\section{Allocation}

We considered both studies at unclear risk of bias for random sequence generation as they provided only vague information about the randomisation process (Antonishak 2015; Bull 2012). Both studies omitted details about allocation sequence concealment and were, therefore, at unclear risk of bias for this domain (Antonishak 2015; Bull 2012).

\section{Blinding}

Antonishak 2015 had a low risk of bias for blinding as participants were not aware of their assignment. Bull 2012 had unclear risk of bias as they reported no details about blinding.

\section{Incomplete outcome data}

Both studies had a high risk of bias for incomplete outcome data reporting as one study reported 30\% loss to follow-up (Antonishak 2015 ), and the second study reported $41 \%$ of controls and $55 \%$ of intervention participants were lost to follow-up at six months (Bull 2012).

In the first study, participants in the intervention group were more likely to be dropped from the 12-month follow-up because they reported they were trying to get pregnant compared to the control group (Antonishak 2015). The authors suggested this may be due to increased awareness of pregnancy desires in the intervention group as a result of using the intervention.

In the second study, the high levels of attrition (of up to $55 \%$ of the intervention group) resulted in the study being underpowered to detect a difference in outcomes between the intervention and control groups (Bull 2012).

\section{Selective reporting}

Both studies were at low risk for selective outcome reporting as all outcomes were reported in the results (Antonishak 2015; Bull 2012).

\section{Other potential sources of bias}

While we appreciate that there are limitations to data collection in sexual health research, both studies relied on self-reported outcomes that may have been liable to misclassification bias and the introduction of social desirability bias with regards to the outcome given the topic area of contraceptive use (Antonishak 2015; Bull 2012). Both studies used online surveys for data collection that may have mitigated this to some extent, compared to other data collection methods, but the risk of bias remained unclear. In terms of selection, although Antonishak 2015 screened potential participants to exclude those who were pregnant or planning to get pregnant, this status might have changed during the period of the trial, while Bull 2012 did not perform such screening.

Additionally, a measurement bias may have been introduced in the analysis of use of more effective contraceptive methods in one study (Antonishak 2015). The analysis selected the most effective self-reported method used by participants in the previous four weeks and transformed the response by coding them on a scale 
of effectiveness. This may have resulted in an overestimate of the effect measure in both the control and intervention groups.

One study utilised multiple recruitment methods, and reported higher representation from areas where face-to-face efforts and newspaper advertising were employed (Bull 2012). This may have introduced a selection bias, as further participants were recruited through an index case and hence limited the generalisability of results to the wider population.
Furthermore, this study also reported $6.8 \%$ of control participants being contaminated (participants in the control group who used the intervention without being allocated to it) (Bull 2012), and it was unclear how these participants were treated in the analysis. Contamination would reduce the ability of the study to detect a difference between control and intervention groups, hence the risk of contamination bias remains unclear.

A summary of the risk of bias assessment for the included studies can be found in the Characteristics of included studies table, Figure 2, and Figure 3.

Figure 2. Risk of bias graph: review authors' judgements about each risk of bias item presented as percentages across all included studies.

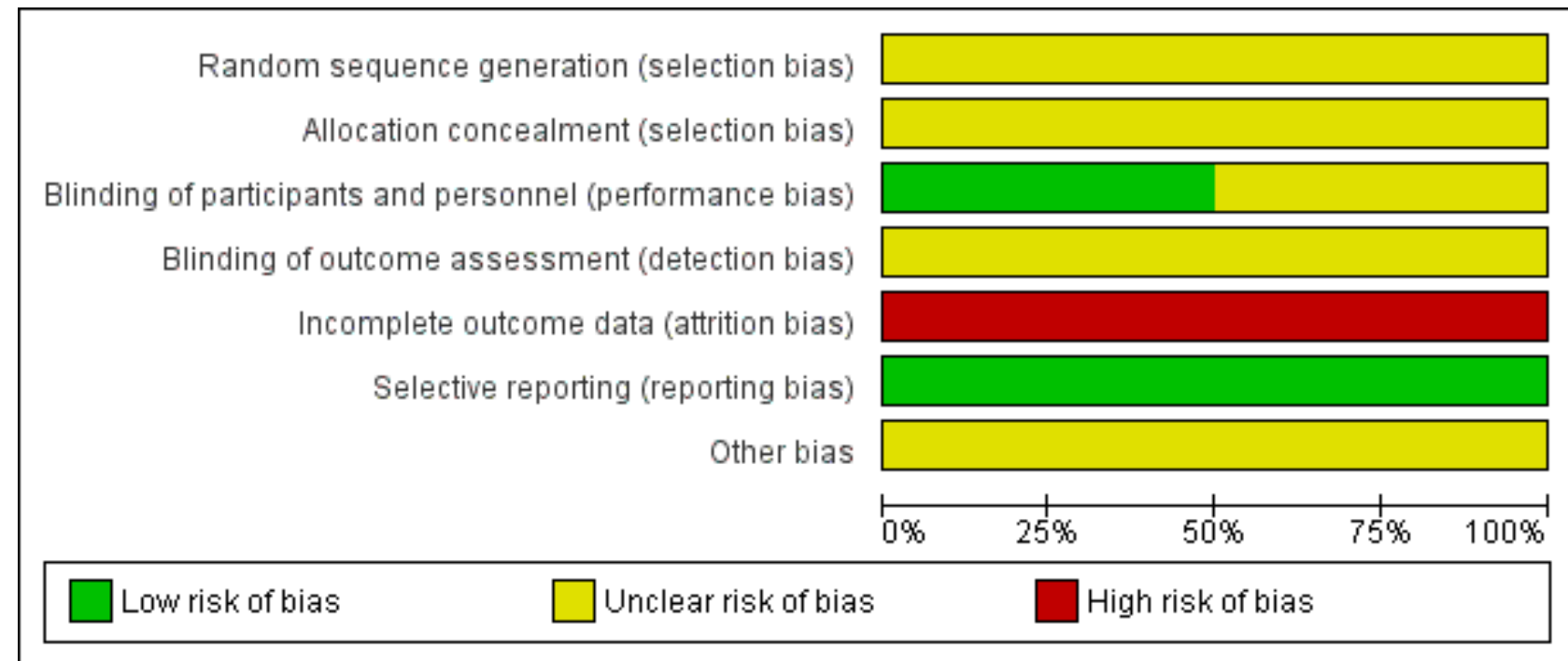


Figure 3. Risk of bias summary: review authors' judgements about each risk of bias item for each included study.

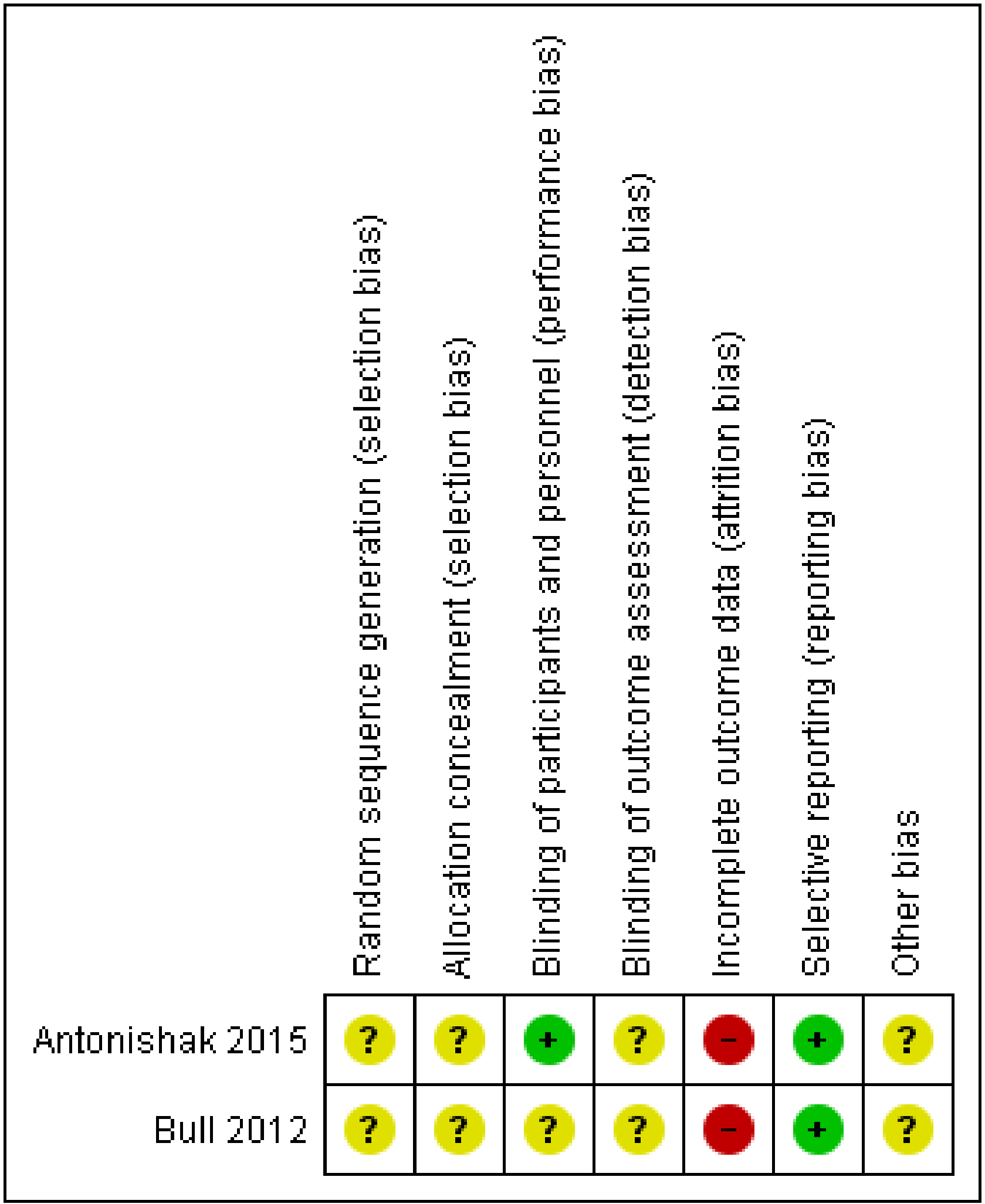

\section{Effects of interventions}

Due to heterogeneity in the study designs and outcomes reported we were unable to conduct a meta-analysis or statistical test of heterogeneity and hence were unable to obtain a pooled result. We reported the intervention efforts descriptively. 


\section{Primary outcomes}

For the primary outcomes, neither study found improved adherence to a contraceptive method for at least three months after the intervention was initiated in their trials. There were no significant differences in aggregated self-reported consistency in use of selected contraceptives (condoms, contraceptive pill, and withdrawal) over 12 months in one study (effect estimate not reported; Antonishak 2015). The second study found no significant difference in condom use at last sexual act at six months between the intervention and control group (Cohen's $d-0.10$, $P$ value not available), and found a non-significant decrease at six months in the overall proportion of sexual acts that were protected by condoms in the last 60 days (Cohen's $d-0.065$, P value not available; Bull 2012).

One study also looked at increased uptake of long-acting reversible methods by reporting the use of more effective methods of contraception, calculated by selecting the self-reported most effective method used in the last four weeks and analysing this on their scale of effectiveness. They found a small significant increase in the overall use of a more effective method of contraception in the intervention group compared to the control group over the 12month trial $(P=0.03$; Antonishak 2015).

Neither study included initiation of a new contraceptive method as a primary outcome measure.

\section{Secondary outcomes}

For the secondary outcome measure, both studies assessed change in contraceptive knowledge. While one study found significantly increased familiarity to eight selected types of contraceptives in the intervention group $(P=0.01)$, there was no significant change in the knowledge of the relative effectiveness of the different methods (effect estimate not reported; Antonishak 2015). Similarly, there was no significant change in condom self-efficacy in the intervention group at six months in the second study (results not reported), but there was a non-significant increase in intention to use condoms in the intervention group (Cohen's $d+0.10, P$ value not available; Bull 2012).

Neither of the studies included attitudes to use of an SNSs as an intervention as an outcome measure.

\section{DISCUSSION}

\section{Summary of main results}

We found little scientific evidence available to support whether SNSs improved initiation and adherence to contraception among reproductive-age women. Of 461 uniquely identified records, only two studies met this review's inclusion criteria and both were assessed at high for risk of bias. One study reported on adherence to selected contraceptive methods (Antonishak 2015), and the second study reported on condom use at last sexual act and over the last 60 days (Bull 2012). Both studies assessed the knowledge gained postintervention but there was no evidence of effect. One study demonstrated an increased use of more highly effective methods of contraception in their intervention group but the increase was small and the results must be interpreted with caution given the study's risk of bias (Antonishak 2015). Neither study reported on any adverse effects. We were unable to perform a meta-analysis due to heterogeneity in study interventions and outcome measures.

\section{Overall completeness and applicability of evidence}

The studies identified were relevant to the review question and assessed interventions using SNSs to promote contraception in women of reproductive age. Of note, one study aimed to assess sexual risk behaviour for which the outcomes measured were centred around condom usage and so remained relevant to this review (Bull 2012).

However, the studies had very limited generalisability as both were conducted in the USA among women aged 16 to 29 years, and hence did not represent the global population, or the whole reproductive age.

Regarding the secondary outcomes, neither study considered the participant's attitude about using SNS as an intervention, hence we found no evidence to comment on the acceptability and feasibility of the intervention.

\section{Quality of the evidence}

The limited body of evidence identified did not allow for a robust conclusion in this review of two studies with 3826 participants from the USA.

The first study used a robust sampling method to reduce selection bias; however, $30 \%$ of their sample was lost to follow-up at 12 months of which they reported $24 \%$ was due to attrition (Antonishak 2015). They reported similar characteristics between those lost to follow-up in the control and intervention groups, with the exception of those in the intervention group being more likely to be excluded if they were trying to get pregnant. They hypothesised that the difference may have been due to the intervention resulting in an increased awareness of pregnancy desires in this group. Regarding the mechanism of action, the authors acknowledged that the findings may not correlate with extent of exposure with the intervention, as no data were collected on content engagement and dose-response.

Outcome measures in this study were self-reported and hence prone to social desirability and misclassification of outcome biases, an issue which is common in sexual health research. However, the use of online responses may have mitigated this to some extent as computer-assisted survey instruments have been found to raise rates of reporting sensitive behaviours (Langhaug 2010). Furthermore the methodology used to calculate most effective contraceptive method by coding the reported most effective method used in the last four weeks is likely to have resulted in an overestimate of effectiveness. However, this would be nondifferential between the intervention and control groups.

The second study utilised cluster design, and recruited participants through multiple media with a referral process (Bull 2012). Clustering was accounted for by assigning networks to the intervention or control group and using modelling, adjusted estimates, and significance tests to account for the nested structure of the data. Selection bias was introduced, as even with increased efforts to recruit higher risk youths, certain areas recruited greater numbers of participants. The study was underpowered due to the significant rates of attrition that were higher in the intervention group (55\% compared to $41 \%$ of controls) and in high-risk youths that are likely to have limited the ability of the study to detect a genuine difference between the intervention and control groups. They reported using a 'full information maximum likelihood 
estimation' model which performs well when data are missing at random, although the higher level of attrition in the intervention group may suggest this was not the case in this study. Additionally the study reported that $6.8 \%$ of the controls were contaminated and had been exposed to the intervention, which introduced a further bias that reduce the ability of detecting a difference between the groups. Lastly, while the study collected aggregate data on engagement with the content there was no analysis of exposure to the intervention and outcomes.

\section{Potential biases in the review process}

The search strategy for this review was independently run by the Cochrane group and incorporated both scientific and computing databases to be as inclusive as possible. However, we were unable to search the SNSs directly, as the methodology for this remains non-systematic and is unlikely to produce replicable results (Gold 2011).

We contacted authors for any missing information and where appropriate requested a breakdown of the result by gender where results were presented as combined for both genders. However, we only received replies on effect estimates from one study (Bull 2012).

\section{Agreements and disagreements with other studies or reviews}

Several systematic reviews have studied social media interventions for sexual health promotion, however the scope generally differed from ours, and focused heavily on sexually transmitted infections rather than contraception and so we cannot infer from these studies.

One systematic review looking at SNSs and sexual health promotion activities identified 178 activities of which only one was found in published scientific literature (Gold 2011). Similarly to our review, most of the activities were based in the USA and Facebook was found to be the most common SNS. However, the review did not assess the impact or effectiveness of the sexual health promotion activities.

A second systematic review had a broader scope and included interventions that use 'new digital media' to improve adolescent sexual health (Guse 2012). Of the 10 included studies, seven were conducted in the USA. Of relevance to our review, they had mixed findings from studies evaluating self-efficacy of condom use and sexual health knowledge. Of interest they found that attitudes towards the interventions themselves were usually positive, however the majority of interventions were website based as opposed to SNSs.

Finally, two systematic reviews looked at the use of SNSs in the wider fields of health behaviour changes (Laranjo 2015) and public health practice (Capurro 2014), where both reviews found Facebook to be the most common SNS used. In one review, $16 \%$ of included studies had sexual health as the behaviour of interest, and a slight positive effect of SNS interventions on health behaviour change was found on meta-analysis (Hedges' g $0.24,95 \% \mathrm{Cl} 0.04$ to 0.43 ; Laranjo 2015). The second review included $29 \%$ of studies that were sexual health focused but found that most of the studies described 'passive approaches' to SNSs rather than a more active approach to its usage (Capurro 2014).

\section{AUTHORS' CONCLUSIONS}

\section{Implications for practice}

There is insufficient research to know whether SNSs improve contraceptive use or adherence among women. Very limited evidence suggests that SNSs may have the ability to increase the use of more effective methods of contraception.

\section{Implications for research}

SNSs could be a feasible platform for public health interventions to address the unmet need for contraception. The failure to find an impact of SNS on contraceptive use or contraceptive adherence among women does not mean that one does not exist. This review clearly demonstrates that further research is needed. The field is lacking in robust reporting of their research and a methodology for conducting research including how to deal with issues of information governance and consent. One way of increasing the evidence base for such interventions is to incorporate contraceptive-related outcomes in studies of general sexual health or just overall health. Future research could also include how health interventions are impacted by changing usage of SNS platforms as well as how SNS health interventions can impact health inequities.

\section{ACKN OWLEDGEMENTS}

The authors and the Fertility Regulation Group Editorial team are grateful to our peer reviewers for their time and comments. 


\section{RE F E R E N C E S}

\section{References to studies included in this review}

Antonishak 2015 \{published data only\}

Antonishak J, Kaye K, Swiader L. Impact of an online birth control support network on unintended pregnancy. Social Marketing Quarterly 2015;21(1):23-36.

\section{Bull 2012 \{published and unpublished data\}}

Bull S, Levine DK, Black SR, Schmiege SJ, Santelli J. Social media-delivered sexual health intervention: a cluster randomized controlled trial. American Journal of Preventive Medicine 2012;43(5):467-74.

\section{References to studies excluded from this review \\ Hidiroglu 2016 \{published data only\}}

Hidiroglu S, Topuzoglu A, Onsuz MF. A community-based intervention programme on hormonal contraceptives: the utilisation of social networks. Journal of Obstetrics and Gynaecology 2016;36(1):126-30.

\section{McCarthy 2017 \{published data only\}}

McCarthy O, Leurent B, Edwards P, Tokhirov R, Free C. A randomised controlled trial of an intervention delivered by app instant messaging to increase the acceptability of effective contraception among young people in Tajikistan: study protocol. BMJ Open 2017;7(9):e017606.

\section{Sun 2017 \{published data only\}}

Sun WH, Wong $\mathrm{CKH}$, Wong WCW. A peer-led, social mediadelivered, safer sex intervention for Chinese college students: randomized controlled trial. Journal of Medical Internet Research 2017;19(8):1.

\section{Additional references}

\section{Alexa 2016}

Alexa. The top 500 sites on the web. www.alexa.com/topsites/ global (accessed 17 May 2016).

\section{Alkema 2013}

Alkema L, Kantorova V, Menozzi C, Biddlecom A. National, regional, and global rates and trends in contraceptive prevalence and unmet need for family planning between 1990 and 2015: a systematic and comprehensive analysis. Lancet 2013;381(9878):1642-52.

\section{Balatsoukas 2015}

Balatsoukas P, Kennedy C, Buchan I, Powell J, Ainsworth J. The role of social network technologies in online health promotion: a narrative review of theoretical and empirical factors influencing intervention effectiveness. Journal of Medical Internet Research 2015;17(6):e141.

\section{Boden 2015}

Boden J, Fergusson D, Horwood L. Outcomes for children and families following unplanned pregnancy: findings from a longitudinal birth cohort. Child Indicators Research 2015;8(2):389-402.

\section{Boyd 2007}

Boyd D, Ellison N. Social network sites: definition, history, and scholarship. Journal of Computer-Mediated Communication 2007;13(1):210-30.

\section{Capurro 2014}

Capurro D, Cole K, Echavarria M, Joe J, Neogi T, Turner A. The use of social networking sites for public health practice and research: a systematic review. Journal of Medical Internet Research 2014;16(3):e79.

\section{Cleland 2012}

Cleland J, Conde-Agudelo A, Peterson H, Ross J, Tsui A. Contraception and health. Lancet 2012;380(9837):149-56.

\section{Cleland 2014}

Cleland J, Shah IH. The contraceptive revolution: focused efforts are still needed. Lancet 2014;381(9878):1604-6.

\section{Endnote X6 [Computer program]}

Thomson Reuters. Endnote X6. Thomson Reuters, 1988-2012.

\section{Finer 2013}

Finer LB, Philbin JM. Sexual initiation, contraceptive use, and pregnancy among young adolescents. Pediatrics 2013;131(5):886-91.

\section{Gold 2011}

Gold J, Pedrana A, Sacks-Davis R, Hellard M, Chang S, Howard S, et al. A systematic examination of the use of online social networking sites for sexual health promotion. BioMed Central Public Health 2011;11:583.

\section{Gold 2012}

Gold J, Pedrana E, Stoove A, Chang S, Howard S, Asselin J, et al. Developing health promotion interventions on social networking sites: recommendations from The FaceSpace Project. Journal of Medical Internet Research 2012;14(1):e30.

\section{GRADEpro GDT 2014 [Computer program]}

GRADE Working Group, McMaster University. GRADEpro GDT. Version (accessed 20 December 2016). Hamilton (ON): GRADE Working Group, McMaster University, 2014.

\section{Guse 2012}

Guse K, Levine D, Martins S, Lira A, Gaarde J, Westmorland W, et al. Interventions using new digital media to improve adolescent sexual health: a systematic review. Journal of Adolescent Health 2012;51(6):535-43

\section{Guyatt 2011}

Guyatt G, Oxman A, Vist G, Kunz R, Brozek J, Alonso-Coello P, et al. GRADE guidelines: rating the quality of evidence - study limitations (risk of bias). Journal of Clinical Epidemiology 2011;64(4):407-15. 


\section{Higgins 2011}

Higgins J, Green S, editor(s). Cochrane Handbook for Systematic Reviews of Interventions Version 5.1.0 (updated March 2011). The Cochrane Collaboration, 2011. Available from handbook.cochrane.org.

\section{Kofinas 2014}

Kofinas J, Varrey A, Sapra K, Kanj R, Chervenak F, Asfaw T. Adjunctive social media for more effective contraceptive counseling: a randomized controlled trial. Obstetrics and Gynecology 2014;123(4):763-70.

\section{Korda 2013}

Korda $\mathrm{H}$, Itani Z. Harnessing social media for health promotion and behavior change. Health Promotion Practice 2013;14(1):15-23.

\section{Kuroki 2008}

Kuroki LM, Allsworth JE, Redding CA, Blume JD, Peipert JF. Is a previous unplanned pregnancy a risk factor for a subsequent unplanned pregnancy?. American Journal of Obstetrics and Gynecology 2008;199(5):517.e1-7.

\section{Langhaug 2010}

Langhaug LF, Sherr L, Cowan FM. How to improve the validity of sexual behaviour reporting: systematic review of questionnaire delivery modes in developing countries. Tropical Medicine \& International Health 2010;15(3):362-81.

\section{Laranjo 2015}

Laranjo L, Arguel A, Neves A, Gallagher A, Kaplan R, Mortimer N, et al. The influence of social networking sites on health behavior change: a systematic review and meta-analysis. Journal of the American Medical Informatics Association 2015;22(1):243-56

\section{Lin 2011}

Lin K, Lu H. Why people use social networking sites: an empirical study integrating network externalities and motivation theory. Computers in Human Behavior 2011;27(3):1152-61.

\section{Moreno 2009}

Moreno M, Vanderstoep A, Parks M, Zimmerman F, Kurth A, Christakis $D$. Reducing at-risk adolescents display of risk behavior on a social networking web site: a randomized controlled pilot intervention trial. Archives of Pediatrics and Adolescent Medicine 2009;163(1):35-41.

\section{Ofcom 2015}

The Office of Communications. Adults; media use and attitudes. Report 2015. www.ofcom.org.uk/__data/assets/pdf_ file/0014/82112/2015_adults_media_use_and_attitudes_ report.pdf (accessed 17 May 2016).

\section{CHARACTERISTICS OF STUDIES}

Characteristics of included studies [ordered by study ID]

\section{Ofcom 2017}

The Office of Communications. Adults' media use and attitudes. Report 2017. www.ofcom.org.uk/_data/assets/ pdf_file/0020/102755/adults-media-use-attitudes-2017.pdf (accessed 11 September 2018).

\section{Pew Research Center 2018}

Pew Research Center. Social media use by gender. pewrsr.ch/2Ql5yo4 (accessed 11 Septemeber 2018).

\section{Statista 2015}

Statista. Daily time spent on social networking by internet users worldwide from 2012 to 2015 (in minutes). www.statista.com/ statistics/433871/daily-social-media-usage-worldwide/ (accessed 17 May 2016).

\section{UN 2015}

United Nations. Trends in contraceptive use worldwide 2015 Department of Economic and Social Affairs (ST/ESA/SER.A/349). www.un.org/en/development/desa/population/publications/ pdf/family/trendsContraceptiveUse2015Report.pdf (accessed 17 May 2016).

\section{Wellings 2007}

Wellings K, Jones KG, Mercer CH, Tanton C, Clifton S, Datta J. The prevalence of unplanned pregnancy and associated factors in Britain: findings from the third National Survey of Sexual Attitudes and Lifestyles (Natsal-3). Lancet 2013;382(9907):1807-16.

\section{WHO 2004}

World Health Organization. Contraception, issues in adolescent health and development. apps.who.int/iris/bitstream/ handle/10665/42901/9241591447_eng.pdf (accessed 17 May 2016).

\section{WHO 2006}

World Health Organization. Reproductive health indicators: guidelines for their generation, interpretation and analysis for global monitoring. apps.who.int/iris/handle/10665/43185 2006.

\section{Xu 2012}

Xu C, Ryan S, Prybutok V, Wen C. It is not for fun: an examination of social network site usage. Information and Management 2012;49(5):210-7.

\section{References to other published versions of this review Jawad 2017}

Jawad A, Jawad I, Alwan NA. Interventions using social networking sites to promote contraception in women of reproductive age. Cochrane Database of Systematic Reviews 2017, Issue 1. [DOI: 10.1002/14651858.CD012521] 
Antonishak 2015

\begin{tabular}{ll}
\hline Methods & $\begin{array}{l}\text { Randomised controlled study over } 12 \text { months } \\
\text { Conducted between } 2012 \text { and } 2013\end{array}$ \\
\hline Participants & 2284 women based in the USA \\
& Age: $18-29$ years \\
\hline Interventions & Use of website (Bedsider.org) with online videos. \\
& Intervention group: participants were shown videos and encouraged to use site. They were also sent \\
& quarterly emails with content. \\
& Control group: no exposure to website.
\end{tabular}

\begin{tabular}{ll}
\hline Outcomes & Primary outcomes \\
& - Improved adherence: condom and pill consistency \\
& - Increased uptake of long-acting reversible methods: scaled use of more effective methods of con- \\
& traception
\end{tabular}

Secondary outcomes

- Change in attitude/knowledge

- Improved knowledge of relative effectiveness of contraceptive methods

Notes Inclusion criteria fulfilled through use of interactive website with appropriate outcome measures.

\begin{tabular}{|c|c|c|}
\hline \multicolumn{3}{|l|}{ Risk of bias } \\
\hline Bias & Authors' judgement & Support for judgement \\
\hline $\begin{array}{l}\text { Random sequence genera- } \\
\text { tion (selection bias) }\end{array}$ & Unclear risk & Not described in sufficient detail. \\
\hline $\begin{array}{l}\text { Allocation concealment } \\
\text { (selection bias) }\end{array}$ & Unclear risk & Not described in sufficient detail. \\
\hline $\begin{array}{l}\text { Blinding of participants } \\
\text { and personnel (perfor- } \\
\text { mance bias) } \\
\text { All outcomes }\end{array}$ & Low risk & Participants blinded to intervention. \\
\hline $\begin{array}{l}\text { Blinding of outcome as- } \\
\text { sessment (detection bias) } \\
\text { All outcomes }\end{array}$ & Unclear risk & Not described in sufficient detail. \\
\hline $\begin{array}{l}\text { Incomplete outcome data } \\
\text { (attrition bias) } \\
\text { All outcomes }\end{array}$ & High risk & $30 \%$ loss to follow-up \\
\hline $\begin{array}{l}\text { Selective reporting (re- } \\
\text { porting bias) }\end{array}$ & Low risk & All outcomes reported. \\
\hline Other bias & Unclear risk & $\begin{array}{l}\text { Misclassification and social desirability bias. } \\
\text { Measurement bias in recording of use of most effective method. }\end{array}$ \\
\hline
\end{tabular}


Bull 2012

\begin{tabular}{l} 
Methods $\quad \begin{array}{l}\text { Cluster randomised study over } 6 \text { months } \\
\text { Conducted between } 2010 \text { and } 2011\end{array}$ \\
\hline
\end{tabular}

\begin{tabular}{ll}
\hline Participants & 1578 males and females based in the USA \\
& Age: $16-25$ years \\
\hline Interventions & Intervention group: availability of a Facebook page with sexual health content \\
& Control group: access to a tailored Facebook news page \\
\hline
\end{tabular}

Primary outcomes
- Improved adherence: condom use at last sexual intercourse
- Improved adherence: proportion of sex acts protected by condoms in the past 60 days
Secondary outcomes
- Change in attitude/knowledge: intention to use condoms at the next sexual encounter
- self-efficacy of condom usage

\section{Risk of bias}

\begin{tabular}{|c|c|c|}
\hline Bias & Authors' judgement & Support for judgement \\
\hline $\begin{array}{l}\text { Random sequence genera- } \\
\text { tion (selection bias) }\end{array}$ & Unclear risk & Not described in sufficient detail. \\
\hline $\begin{array}{l}\text { Allocation concealment } \\
\text { (selection bias) }\end{array}$ & Unclear risk & Not described in sufficient detail. \\
\hline $\begin{array}{l}\text { Blinding of participants } \\
\text { and personnel (perfor- } \\
\text { mance bias) } \\
\text { All outcomes }\end{array}$ & Unclear risk & Not described in sufficient detail. \\
\hline $\begin{array}{l}\text { Blinding of outcome as- } \\
\text { sessment (detection bias) } \\
\text { All outcomes }\end{array}$ & Unclear risk & Not described in sufficient detail. \\
\hline $\begin{array}{l}\text { Incomplete outcome data } \\
\text { (attrition bias) } \\
\text { All outcomes }\end{array}$ & High risk & High attrition with $41 \%$ of controls and $55 \%$ of intervention participants. \\
\hline $\begin{array}{l}\text { Selective reporting (re- } \\
\text { porting bias) }\end{array}$ & Low risk & All outcomes reported. \\
\hline Other bias & Unclear risk & $\begin{array}{l}\text { Misclassification and social desirability bias. } \\
\text { Selection bias through recruitment methods. } \\
\text { Contamination bias. }\end{array}$ \\
\hline
\end{tabular}


Characteristics of excluded studies [ordered by study ID]

\begin{tabular}{ll}
\hline Study & Reason for exclusion \\
\hline Hidiroglu 2016 & Excluded as intervention was not a social networking site. \\
\hline McCarthy 2017 & Excluded as the intervention could only be utilised when downloaded. \\
\hline Sun 2017 & Excluded as timeframe for outcome assessment $<3$ months. \\
\hline
\end{tabular}

\section{APPENDICES}

\section{Appendix 1. Search strategies}

\section{Search strategy}

\section{Search terms}

\section{CENTRAL}

\begin{tabular}{|c|c|}
\hline 1 & CONTRACEPTION/ EXP \\
\hline 2 & CONTRACEPTION BEHAVIOUR/ EXP \\
\hline 3 & CONTRACEPTIVE AGENTS/ EXP \\
\hline 4 & CONTRACEPTIVE DEVICES/ EXP \\
\hline 5 & FAMILY PLANNING SERVICES/ EXP \\
\hline 6 & Contracept* \\
\hline 7 & Condom* \\
\hline 8 & Contraceptive agent \\
\hline 9 & Barrier contracepti* \\
\hline 10 & Family planning \\
\hline 11 & Emergency contracept $^{\star}$ \\
\hline 12 & Intrauterine contracept ${ }^{\star}$ device $^{\star}$ \\
\hline 13 & Postcoital contracept ${ }^{\star}$ \\
\hline 14 & Or $1-13$ \\
\hline 15 & SOCIAL MEDIA/ \\
\hline 16 & Social Media \\
\hline
\end{tabular}




\begin{tabular}{ll}
\hline 17 & Social network \\
\hline 18 & Facebook \\
\hline 19 & Twitter \\
\hline 20 & Instagram \\
\hline 21 & Snapchat \\
\hline 22 & Myspace \\
\hline 23 & Or 15-22 \\
\hline 24 & 14 AND 23
\end{tabular}

\section{MEDLINE}

\begin{tabular}{|c|c|}
\hline 1 & CONTRACEPTION/ EXP \\
\hline 2 & CONTRACEPTION BEHAVIOR/ \\
\hline 3 & CONTRACEPTIVE AGENTS/ EXP \\
\hline 4 & CONTRACEPTIVE DEVICES/ \\
\hline 5 & FAMILY PLANNING SERVICES/ \\
\hline 6 & CONDOMS/ \\
\hline 7 & Contracept ${ }^{\star}$ \\
\hline 8 & Condom* \\
\hline 9 & Contraceptive agent \\
\hline 10 & Barrier contracepti* \\
\hline 11 & Family planning \\
\hline 12 & Emergency contracept* \\
\hline 13 & Intrauterine contracept ${ }^{\star}$ device ${ }^{\star}$ \\
\hline 14 & Postcoital contracept ${ }^{\star}$ \\
\hline 15 & OR $1-14$ \\
\hline 16 & SOCIAL MEDIA/ EXP \\
\hline 17 & SOCIAL NETWORKING/ EXP \\
\hline 18 & Social Media \\
\hline 19 & Social network* \\
\hline
\end{tabular}




\begin{tabular}{ll}
20 & Facebook \\
\hline 21 & Twitter \\
\hline 22 & Instagram \\
\hline 23 & Snapchat \\
\hline 24 & Myspace \\
\hline 25 & OR 16-24 \\
\hline 26 & 15 AND 25
\end{tabular}

\section{Embase}

\begin{tabular}{|c|c|}
\hline 1 & CONTRACEPTION/ EXP \\
\hline 2 & CONTRACEPTIVE/ \\
\hline 3 & CONTRACEPTIVE AGENT/ \\
\hline 4 & CONTRACEPTIVE BEHAVIOUR/ \\
\hline 5 & CONTRACEPTIVE DEVICE \\
\hline 6 & FAMILY PLANNING/ \\
\hline 7 & Contracept ${ }^{\star}$ \\
\hline 8 & Condom* \\
\hline 9 & Contraceptive agent \\
\hline 10 & Barrier contracepti* \\
\hline 11 & Family planning \\
\hline 12 & Emergency contracept ${ }^{*}$ \\
\hline 13 & Intrauterine contracept ${ }^{\star}$ device ${ }^{\star}$ \\
\hline 14 & Postcoital contracept ${ }^{\star}$ \\
\hline 15 & OR 1-14 \\
\hline 16 & SOCIAL NETWORK/ \\
\hline 17 & SOCIAL MEDIA/ \\
\hline 18 & Social Media \\
\hline 19 & Social network* \\
\hline 20 & Facebook \\
\hline
\end{tabular}




\begin{tabular}{ll}
21 & Twitter \\
\hline 22 & Instagram \\
\hline 23 & Snapchat \\
\hline 24 & Myspace \\
\hline 25 & OR 16-24 \\
\hline 26 & 15 AND 25
\end{tabular}

\section{CINAHL}

\begin{tabular}{|c|c|}
\hline 1 & CONTRACEPTION/ EXP \\
\hline 2 & REPRODUCTIVE CONTROL AGENTS/ EXP \\
\hline 3 & CONTRACEPTIVE DEVICES/ EXP \\
\hline 4 & Contracept ${ }^{\star}$ \\
\hline 5 & Condom* \\
\hline 6 & Contraceptive agent \\
\hline 7 & Barrier contracepti* \\
\hline 8 & Family planning \\
\hline 9 & Emergency contracept ${ }^{\star}$ \\
\hline 10 & Intrauterine contracept ${ }^{\star}$ device $^{\star}$ \\
\hline 11 & Postcoital contracept ${ }^{\star}$ \\
\hline 12 & OR $1-11$ \\
\hline 13 & SOCIAL NETWORKING/ \\
\hline 14 & SOCIAL MEDIA/ \\
\hline 15 & Social Media \\
\hline 16 & Social network* \\
\hline 17 & Facebook \\
\hline 18 & Twitter \\
\hline 19 & Instagram \\
\hline 20 & Snapchat \\
\hline 21 & Myspace \\
\hline
\end{tabular}


(Continued)

22 23

\section{Web of Science}

\begin{tabular}{|c|c|}
\hline 1 & $\mathrm{TS}=$ contracept $^{\star}$ \\
\hline 2 & TS $=$ contracepti $^{\star}$ agent $^{\star}$ \\
\hline 3 & TS=emergency contracepti ${ }^{\star}$ \\
\hline 4 & $\mathrm{TS}=$ postcoital contraception \\
\hline 5 & $\mathrm{TS}=$ contracept $^{\star}$ devices $^{\star}$ \\
\hline 6 & $\mathrm{TS}=$ condom \\
\hline 7 & TS=barrier contraception \\
\hline 8 & TS=family planning \\
\hline 9 & OR 1-8 \\
\hline 10 & TS=Social Media \\
\hline 11 & TS=Social network ${ }^{\star}$ \\
\hline 12 & $\mathrm{TS}=$ Facebook \\
\hline 13 & TS=Twitter \\
\hline 14 & TS=Instagram \\
\hline 15 & TS=Myspace \\
\hline 16 & TS= Snapchat \\
\hline 17 & OR $10-16$ \\
\hline 18 & 9 AND 17 \\
\hline
\end{tabular}

\section{Association for Computing Machinery}

\begin{tabular}{ll}
\hline 1 & Contracept $^{\star}$ \\
\hline 2 & Condom $^{\star}$ \\
\hline 3 & Contraceptive agent \\
\hline 4 & Barrier contracepti \\
\hline 5 & Family planning \\
\hline 6 & Emergency contracept \\
\hline
\end{tabular}




\begin{tabular}{|c|c|}
\hline 7 & Intrauterine contracept* device* \\
\hline 8 & Postcoital contracept* \\
\hline 9 & OR $1-8$ \\
\hline 10 & Social Media \\
\hline 11 & Social network* \\
\hline 12 & Facebook \\
\hline 13 & Twitter \\
\hline 14 & Instagram \\
\hline 15 & Snapchat \\
\hline 16 & Myspace \\
\hline 17 & OR $10-16$ \\
\hline 18 & 9 AND 17 \\
\hline
\end{tabular}

\section{DBPL Computer Science Bibliography}

\begin{tabular}{|c|c|}
\hline 1 & Contracept $^{\star}$ \\
\hline 2 & Condom* \\
\hline 3 & Contraceptive agent \\
\hline 4 & Barrier contracepti* \\
\hline 5 & Family planning \\
\hline 6 & Emergency contracept ${ }^{\star}$ \\
\hline 7 & Intrauterine contracept ${ }^{\star}$ device ${ }^{\star}$ \\
\hline 8 & Postcoital contracept ${ }^{\star}$ \\
\hline 9 & OR $1-8$ \\
\hline 10 & Social Media \\
\hline 11 & Social network* \\
\hline 12 & Facebook \\
\hline 13 & Twitter \\
\hline 14 & Instagram \\
\hline 15 & Snapchat \\
\hline
\end{tabular}




$\begin{array}{ll}17 & \text { OR } 10-16\end{array}$

\title{
CONTRIBUTIONS OF AUTHORS
}

A Jawad: designed the review; collected and analysed the data; wrote the first draft of the manuscript; and contributed to and approved the final draft of the manuscript.

I Jawad: collected and analysed the data, contributed to the draft manuscript, and approved the final draft of the manuscript.

N Alwan: contributed to designing the review, contributed to the draft manuscript, and approved the final draft of the manuscript.

\section{DECLARATIONSOF INTEREST}

\author{
A Jawad: none. \\ I Jawad: none. \\ N Alwan: none.
}

\section{SOURCES OF SUPPORT}

\section{Internal sources}

- None, Other.

\section{External sources}

- University of Southampton, UK.

The University of Southampton employs Dr Alwan

\section{DIFFERENCES BETWEEN PROTOCOLANDREVIEW}

Due to the nature of included studies, and effect estimates reported, we were unable to conduct further data synthesis and report summary effect estimates. We had planned to determine odds ratios and $95 \% \mathrm{Cls}$ for dichotomous outcomes and mean difference with $95 \% \mathrm{Cls}$ for continuous variables. However, we were unable to obtain adequate data from included studies to determine these effect measures.

Furthermore, the heterogeneity in the way outcomes were collected and reported prevented us from being able to meaningfully summarise the results into a 'Summary of findings' table, which we had set out to do in the protocol (Jawad 2017).

\section{N DEX TERMS}

\section{Medical Subject Headings (MeSH)}

*Health Knowledge, Attitudes, Practice; *Online Social Networking; Condoms [statistics \& numerical data]; Contraception [ ${ }^{\star}$ statistics \& numerical data]; Contraception Behavior [ ${ }^{\star}$ statistics \& numerical data]; Randomized Controlled Trials as Topic; Sexual Health [* statistics \& numerical data]

\section{MeSH check words}

Adolescent; Adult; Female; Humans; Middle Aged; Young Adult 